\title{
An Apparatus for Rearing Marine Organisms in the Laboratory
}

\author{
By Dr. F. G. Walton Smith (Commonwealth Research Fellow)
}

$\mathrm{A}^{\mathrm{L}}$ LTHOUGH the life-histories of the most important marine organisms have been worked out in the past, there is very little known in many cases regarding the detailed changes that take place during the critical stages separating larval life from that of the adult, while the study of the physiology of invertebrate larvæ has been almost entirely neglected.

These gaps in our knowledge are partly due to the minute size of many of the larvæ, but also in large measure to the difficulty experienced in rearing them in the laboratory. Even though the most scrupulous care be taken in sterilising instruments and vessels, and in keeping physical and chemical conditions of the environment 'normal', this difficulty remains; and it is a common experience to find that larvæ will live in plunger jars for days and weeks longer than the natural period of their freeswimming existence without increasing in size or developing organs characteristic of the metamorphosing stages. On the other hand, attempts to provide food in the form of organisms isolated from the microplankton, though occasionally successful, are usually doomed to failure, owing to the ease with which the physical, chemical and biological factors of the environment in a restricted volume of water pass beyond our control, and to our ignorance of the actual food requirements.

If, however, a continuous flow of fresh sea-water can be supplied to the organisms in sufficient quantity, not only will physical and chemical conditions remain stable, but also food organisms of the kind available under natural conditions will be provided, and in sufficient concentration to permit of normal growth and development. It was found necessary recently, in order to study the metamorphosis and biology of the larval oyster, to construct an apparatus that would satisfy this requirement, and make it possible to undertake the rearing of all stages in development with a high degree of certainty. The apparatus (Fig. 1) and procedure described below have given consistently satisfactory results, not only with the larvæ of the common American oyster, but also with later stages of Ostrea equestris, and species of Chiton, Crepidula and Fissurella.

The type of vessel employed is the cylindrical jar used in some fish hatcheries, and is about $18 \mathrm{in.} \mathrm{high}$ and 6 in. in diameter, with a conical base $(B)$. This shape has the advantage that on stopping the flow of water the larvæ quickly settle to the bottom and are readily collected. In order that the flow of water may not earry away the small larvæ (early stages of Ostrea virginica are less than $0.06 \mathrm{~mm}$. in smallest dimension), the outflowing water is removed from the rearing jar by means of a siphon $\left(S_{3}\right)$, the wide mouth of which $\left(F_{2}\right)$ is covered by a fine net of bolting silk. Rapid clogging of the pores of this material is prevented by dipping the mouth of the siphon under the surface of molten paraffin wax melting at a temperature of $48^{\circ} \mathrm{C}$. and then blowing air through the other end as it is removed. The resulting smooth coating of wax on the fibres of the net seems to prevent the entanglement of the larvæ, and allows the filter to work efficiently for a much longer period than otherwise would be the case. The net is fitted to the siphon by means of a rubber band.

The sea-water supply is taken from the reservoir feeding the main laboratory circulation, replenished by pumping from the sea once or twice a week. Where there is no such source of supply, it is necessary to use a supply tank which is replenished when needful with sea-water taken at high tide.

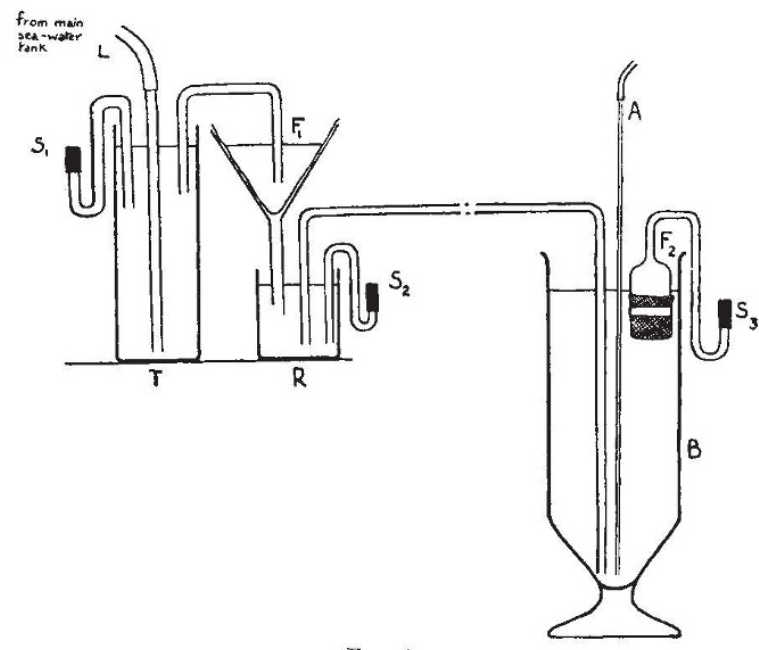

FIG. 1.

Whereas the exit siphon is placed at the top of the jar, the sea-water enters the vessel through a glass tube extending to the bottom of it, thus making a good circulation of water possible. It is important that the sea-water supply should also be filtered, and to the same extent as the outflow, in order to guard against the accumulation of detritus and the admission of predatory organisms. This is conveniently carried out by means of a square piece of bolting silk supported in a filter funnel $\left(F_{1}\right)$. Aeration and circulation of the sea-water in the jar are accomplished by means of a glass tube $(A)$ connected with a compressed air supply and extending to the base of the jar.

In order to prevent the sea-water from entering the jar faster than it is removed, with subsequent loss of the larvæ, and in order to prevent an overflow from the filter funnel, a constant level siphon $\left(S_{2}\right)$ is attached to the reservoir $(R)$ supplying the rearing jar, and a similar arrangement is fitted to a vessel $(T)$ feeding the filter. The constant-level siphons may be adjusted by means of small pieces of rubber tubing on the outer arms. The rate of flow of the sea-water through the rearing jar is regulated in this way, and is dependent upon the vertical distance between the outflow of siphons $S_{2}$ and $S_{3}$.

The use of this apparatus is not confined to the rearing of organisms alone. A series of rearing jars may be connected to the same supply reservoir, and if eggs from a single artificial fertilisation are dis. tributed among them in equal numbers, they will 
be able to develop under exactly similar conditions, providing a basis from which biological and physicochemical conditions may be varied for experimental purposes. In order to analyse food requirements, for example, jars to which food organisms and solutions of different kinds are added, and which are supplied with sea-water filtered through a porcelain candle filter, may be set up for comparison with the arrangement previously described.
This apparatus has been found to give a sufficient approximation to 'normal' conditions to enable larvæ to be reared through the most critical stages of development, while in use at the Beaufort, N.C., station of the U.S. Bureau of Fisheries, this summer. My acknowledgments are due to the Bureau and to Dr. Herbert F. Prytherch, director of the Station, for hospitality and advice accorded to me during the time when I was making use of it there.

\section{Archæological Research in Western China}

\begin{abstract}
$A^{\text {LTHOUGH archæological research in China has }}$ $A$ not yet afforded confirmation of the annals of the third millennium B.C., with which its recorded traditions open, excavation in the north and centre has brought to light not only cultures of the neolithic and bronze ages, but also inscriptions in a primitive script, which in a measure corroborate tradition and justify the attribution of authenticity to the dynasty of a period of some centuries before that of Cheo (1122 в.c.), hitherto regarded as the earliest dynastic record worthy of any degree of credence. The west must now be added to the regions of China in which archæological research has produced not only evidence of early civilisation, but also corroboration of a record which stands in a different category.
\end{abstract}

Recent excavations at Hanchow (J. West China Border Research Society, 6, 1933-34) point to an early cultural connexion of the west of China with the north and centre, which may even go back to a much earlier date, if, as is suggested by an eminent Chinese scholar, Dr. Ko Mo Jo, an inseription on bone tablets from Anyang, which records the appearance of men of Shuh in the fighting ranks, and belongs to the Yin dynasty (1400-1122 B.c.), may be taken to refer to Szechwan, of which the ancient name is Shuh. For the fortunate result by which this important addition has been made to knowledge of the prehistoric cultures of China, archæology is indebted to members of the West China Border Research Society, and more especially to Dr. David Graham, curator of the West China Union University Museums, who intervened at a crucial moment to guide the zeal of the Chinese authorities for excavation into channels which would ensure the scientific value of the investigation.

The excavation at Hanchow is one only of a number of activities in which the West China Border Research Society, which was founded in 1922, acting in close co-operation with the Union University, is promoting the advancement of scientific research in the extremely interesting and important border area of western China and eastern Tibet. Its headquarters at Chengtu serve as a focusing point for activities in geographical exploration and studies in anthropology, botany, zoology and medical science, which carry on the scientific work of members of the missionary bodies, who promoted the West China Union University. By their own researches and by their co-operation with members of other scientific expeditions, they did much to promote scientific knowledge of this region long before the University came into being in 1910. The University Museums, which now have 53,334 specimens, distributed among the three Museums of Archæology, Art and Ethnology, the Natural History Museum and the Museum of Medical and Dental Sciences, owe much to their efforts, especially in the ethnographical section, which contains material such as eannot be found in any other museum. The Society's journal, now in its sixth volume, contains much valuable matter, especially worthy of regard in the anthropological world, as the Society, both in its publications and in the organisation of research among its members, is bound in the terms of its constitution to concentrate on regional and other investigations which bear on problems relating to the little-known non-Chinese peoples of the area.

As regards the excavations at Hanchow referred to above, the accidental discovery in 1931 of stone and jade rings, knives, discs and other objects in a pit at T'ai-p'ing-ch'ang, eighteen $l i$ from Hanchow, when an irrigation ditch was being deepened, pointed to the possibility of a prehistoric burial, which was confirmed by systematic excavation in 1934. In addition to the original pit, the ground immediately surrounding was carefully explored and several points in the area were also tested. No further grave pits were found, but everywhere there was abundant material which appeared to be mainly the refuse from a group of ancient pottery kilns.

The preliminary account of the excavation includes also an analysis of the physical characters of the jade and stone objects by Prof. D. S. Pye and of the pottery by Prof. H. B. Collier. A comparison of the culture with that found at Yang Shao and Anyang in Honan and that from Sha Kuo T'un in Fengtien points to interesting resemblances as well as differences. Thus there is no painted pottery at Hanchow or Sha Kuo T'un such as was found by Dr. J. G. Andersson at Yang Shao. Both the Han. chow and the Yang Shao cultures have large and small stone axes, chisels, knives, pestles or hammers, and flat discs, and both incised and cord-marked pottery. In both the potter's wheel is known. At neither, nor at Sha Kuo T'un, is there metal; whereas at Anyang there is abundant bronze, associated with a primitive writing on bone, bone implements and painted pottery.

Though Yang Shao and Sha Kuo T'un are classed as neolithic, the use of the wire saw at Hanchow and resemblances to Cheo objects suggest that the Hanchow site is later than æneolithic. In all probability it cannot be later than the beginning of the Cheo dynasty (1122 B.C.); but it is almost certainly later than the bronze culture of Anyang, which belongs to the Yin dynasty (1400-1122 B.c.). Thus it must represent a retarded development of the west. 